\title{
A Indústria de Móveis em Londrina
}

\section{The Furniture Industry In Londrina}

\author{
Viviane Mazetto Romano da Silva ${ }^{1}$; Marcia Regina Gabardo da Camara ${ }^{2}$
}

\author{
Resumo
}

\begin{abstract}
A indústria moveleira brasileira está organizada em clusters. Clusteré um aglomerado de empresas localizadas em uma determinada região que desenvolvem suas atividades de forma articulada e com uma lógica em comum e cuja dinâmica pode ser determinada pelo fato dessas empresas realizarem atividades semelhantes e/ou utilizarem mão-deobra específica, ou utilizarem as mesmas matérias-primas, etc. A interação e a sinergia, decorrentes da atuação articulada, proporcionam ao conjunto de empresas vantagens competitivas que se refletem em um desempenho diferenciado superior em relação à atuação isolada de cada empresa. .As empresas aglomeradas geograficamente, principalmente de pequeno/médio porte, vêm apresentando recentemente êxito no que se refere à competitividade, geração de empregos, inovações tecnológicas, etc. Na região de Londrina-PR, encontra-se um aglomerado geográfico de empresas produtoras de móveis, com destaque para os móveis residenciais e de escritório. O estudo procurou identificar se a aglomeração geográfica de empresas moveleiras na região corresponde ou não a um cluster. Constatouse um grande potencial para o desenvolvimento do mesmo, devido à proximidade com clientes e fornecedores e em relação à infra-estrutura disponível de serviços. Entretanto, não foi verificada nenhuma forma de ação cooperativa entre empresas ou entre empresas que desenvolvam atividades complementares, também não foi verificada nenhuma instituição ou associação de apoio para as empresas. Conclui-se que na região de Londrina, o cluster é insipiente pois a despeito da aglomeração de empresas, devido aos baixos elos verticais e ausência de elos horizontais e multilaterais que caracterizam clusters mais avançados os efeitos sinergéticos da aglomeração não são verificados.
\end{abstract}

Palavras-chave: Cluster. Competitividade. Moveleira.

\begin{abstract}
The Brazilian furniture industry is organized in clusters. Cluster is an agglomerate of located companies in a certain area that you/they develop their activities in an articulate way and with a logic in common and whose dynamics depends on the fact that those companies accomplish similar activities, use specific labor and raw materials, etc. inducing interaction and synergy, due to articulated performance, they provide to the group of companies competitive advantages that are reflected in an differentiated performance. The companies agglomerated geographically, mainly SMEs - small and medium enterprises - present success - greater competitiveness, generation of jobs, technological innovations, etc. In the area of Londrina - PR, there is a geographical agglomerate of companies producing of pieces of furniture, with prominence for the residential pieces of furniture and of office. The study tried to identify if the geographical gathering of furniture companies in the area corresponds or not to a cluster. A great potential was verified for the development of the same, due to the proximity with customers and suppliers and in relation to the available infrastructure of services. However, any form of cooperative action was not verified among companies or enter companies to develop complementary activities, it was not also verified any institution or support association for the companies. It is concluded that in the area of Londrina, the cluster is incipient because in spite of the gathering of companies, due to the low vertical links and absence of horizontal and multilateral links that characterize more advanced clusters, the synergetic effects of the gathering are not verified.
\end{abstract}

Key Words: Cluster. Competitiveness. Furniture Industry.

Graduada do Curso de Economia - UEL -bolsista PIBIC CNPq e-mail viromano@uol.br

2 Doutora - Professora do Depto. de Economia -UEL e-mail mgabardo@sercomtel.com..br 


\section{Introdução}

A globalização e abertura comercial alteraram a dinâmica da competição organizacional introduzindo novas formas de cooperação entre as empresas. A capacidade de adaptação, flexibilização e de realizar alianças estratégicas vem sendo considerada mais importante que o tamanho da organização em si. A indústria brasileira de móveis tem demonstrado uma grande capacidade empresarial de adaptação nesse novo ambiente de intensa competitividade.

O artigo verifica se há formação de um cluster moveleiro na região de Londrina - PR e o seu grau de desenvolvimento. Procura identificar também os elementos para capacitação de inovações, incorporação de novas tecnologias, fontes para o desenvolvimento de design, os canais de comercialização dos insumos e dos produtos finais, a interação dos agentes para o desenvolvimento de um cluster regional e as políticas públicas que poderiam contribuir para o aumento da eficiência competitiva das empresas localizadas na região.

A amostra foi composta por empresas moveleiras das cidades de Londrina, Cambé, Ibiporã e Rolândia. As empresas foram selecionadas de maneira aleatória simples, sendo permitido um erro amostral de $10 \%$. O porte das empresas analisadas foi definido a partir do número de funcionários e o método utilizado na pesquisa foi o descritivo, pois expõe características de determinada população ou determinado fenômeno. O pesquisador não teve controle sobre as variáveis de modo a manipulá-las, ou seja, somente relata o que está acontecendo com a amostra escolhida. Esse estudo caracteriza como estatístico, está voltado para a amplitude e não para a profundidade. As hipóteses são testadas quantitativamente e as generalizações sobre os resultados são apresentadas com base na representatividade da amostra.

Este artigo se desenvolve em 4 seções: a primeira trata da fundamentação teórica, a segunda discute o desempenho da atividade moveleira no Brasil e no mundo, a terceira apresenta os resultados da configuração do cluster moveleiro na região de
Londrina e por último as notas conclusivas sobre o estudo.

\section{Fundamentação Teórica}

A exposição ao ambiente competitivo internacional ao longo dos anos noventa fez com que a indústria nacional evoluísse em um ambiente de elevada incerteza. As empresas adotaram estratégias de sobrevivência não modernizadoras, ou seja, não se avançou em direção a um perfil moderno de atividades de elevada densidade tecnológica (CASSIOLATO; LASTRES, 2003).

Segundo Possas (1993, p.206), do ponto de vista da empresa, a competitividade "é o poder de definir (formular e implementar) estratégias de valorização do capital, desde que baseado em aspectos econômicos e não institucionais", ou melhor, desde que não esteja fundado em garantias legais. As dimensões competitivas estão relacionadas às características do mercado e estas podem ser de dois tipos. A primeira se refere aos traços relacionados ao produto em si, seus possíveis usos, seus insumos, o processo de fabricação e seu ciclo de vida. Essas vantagens estão presentes em todas as partes do mundo. O segundo conjunto de características é formado pelos elementos locais, regionais ou nacionais e decorrem de aspectos geográficos, culturais, político-institucionais ou econômicos, ou melhor dizendo, são vantagens especificas.

A localização da empresa é um elemento chave para definir a competitividade, uma vez que os vínculos entre empresas, clientes e outras instituições afetam as vantagens competitivas, através do aumento da produtividade do cluster. A alta competitividade enfrentada por diversos setores em nossa economia tem exigido a busca por caminhos alternativos e inovadores que os levem a conquistar resultados positivos. Um desses caminhos é a formação de arranjos produtivos ou clusters (SERCONI, 2003).

A CNI (Confederação Nacional da Indústria do Brasil) conceitua cluster como agrupamento, numa 
referência geográfica, a aglomeração de empresas ali localizadas que desenvolvem suas atividades de forma articulada e com uma lógica econômica comum, a partir, por exemplo, de uma data dotação de recursos naturais, da existência de capacidade laboral, tecnológica ou empresarial local, e da afinidade setorial dos seus produtos. A interação e a sinergia, decorrentes da atuação articulada, proporcionam ao conjunto de empresas vantagens competitivas que se refletem em um desempenho diferenciado superior em relação à atuação isolada de cada empresa (DIAS; PEDROZO, 2002).

Segundo o SEBRAE (2002), as empresas que compõem um cluster, além da proximidade física e da forte relação com os agentes da localidade, tem em comum uma mesma dinâmica econômica. Contudo, tal dinâmica pode ser determinada por razões bastante diversas. Assim, por exemplo, a dinâmica de um cluster de empresas pode ser determinada pelo fato dessas empresas realizarem atividades semelhantes e/ou utilizarem mão-de-obra específica disponível em poucas regiões, ou utilizarem as mesmas matérias-primas, ou necessitarem das mesmas condições climáticas ou de solo para sua produção, por fornecerem para um mesmo cliente que exige proximidade, por processos históricos e culturais, etc.

Para Cassiolato e Lastres (2003), os clusters ou arranjos produtivos apresentam fortes vínculos envolvendo agentes localizados no mesmo território; incluindo não apenas empresas (produtora, fornecedoras, prestadora de serviços, comercializadoras, etc) e suas diversas formas de representação e associação (particularmente cooperativas), mas também diversas outras instituições públicas e privadas (voltadas à formação e treinamento de recursos humanos; pesquisa, desenvolvimento e engenharia; consultoria; promoção e financiamento, etc.). Entende-se a interação, particularmente aquela visando à inovação, entre esses diferentes agentes como importante fonte geradora de vantagens competitivas.
Para Porter (1998), aglomerados ou clusters afetam a competição em três formas mais amplas: (1) incrementando a produtividade de empresas baseadas na área; (2) conduzindo a direção e a velocidade da inovação, que guia o crescimento da produtividade; (3) estimulando a formação de novos negócios, o que permite ao aglomerado crescer e se fortalecer. Participar de um aglomerado viabiliza maior eficiência na busca de matéria-prima, acesso a informações e tecnologia, parcerias, e mensuração e motivação para melhorias. $\mathrm{O}$ acesso à mão-deobra especializada e funcionários experientes, além de facilitar a busca, podem significar custos reduzidos no recrutamento e seleção. As condições relativamente estáveis de um cluster e as oportunidades de emprego podem atrair pessoal de alto potencial produtivo de outras regiões.

Cunha, Oliveira e Cunha (2003) apresentam uma conformação interna para os clusters industriais que geralmente incluem:

a) uma grande empresa ou uma concentração de empresas semelhantes e a identificação das suas relações a montante e jusante;

b) setores que utilizam fornecedores comuns ou fornecem produtos ou serviços complementares;

c) empresas ou instituições que fornecem qualificações especializadas, tecnologias, informações capital, infra-estrutura e associações de classe;

d) agências governamentais e outros órgãos reguladores que exerçam influência sobre a aglomeração.

A aglomeração de arranjos produtivos locais tem auxiliado pequenas e médias empresas a ultrapassarem conhecidas barreiras ao crescimento das firmas, a produzirem eficientemente e a comercializarem produtos em mercados distantes (CASSIOLATO; LASTRES, 2003).

Os clusters aparecem como uma alternativa que proporciona o surgimento de novos negócios, diminui os riscos, possibilita o aumento de emprego para os 
indivíduos que vivem na região, geram importantes potencialidades para a inovação, o que é fundamental para a competitividade no cenário econômico presente.

Esta concentração setorial e geográfica, especialmente de pequenas e médias empresas, pode gerar uma série de benefícios diretos aos seus membros, obtidos através de um conjunto de fatores facilitadores, que são a divisão do trabalho e da especialização entre os produtores, a estipulação da especialidade de cada produtor, o surgimento de fornecedores de matéria-prima e de máquinas, o surgimento de agentes que vendam para mercados distantes, o surgimento de empresas especialistas em serviços tecnológicos, financeiros e contábeis, o surgimento de uma classe de trabalhadores assalariados com qualificações e habilidades específicas e o surgimento de associações para a realização de lobby e de tarefas específicas para o conjunto de seus membros. Tudo isso, representa o conceito de eficiência coletiva, o que não garante, entretanto, que todas as empresas do aglomerado obtenham o mesmo sucesso, algumas podem crescer e outras decair (HUMPHREY; SCHMITZ apud SERCONI, 2003).

Para potencializar o desenvolvimento de clusters, segundo Cunha e Todero (2001), as ações devem ser orientadas para:

- elevar o grau e a natureza da concentração e aglomeração de empresas, buscando especialização flexível e eficiência coletiva;

- facilitar o acesso ao crédito para elevar a taxa de investimento da empresas já existentes e atrair novos investimentos;

- adensamento da cadeia produtiva (insumos, bens de capital e serviços)

- identificação de nichos de mercado;

- formação e capacitação de recursos humanos;

- fortalecimento da articulação com o sistema de inovação, mediante investimentos em pesquisa e desenvolvimento tecnológico;
- ambiente institucional que propicie a articulação entre as entidades empresariais e os governos estaduais e locais.

O cluster está ligado à cooperação, competição e redes. O ambiente competitivo oferece a formação de redes. A solução para as PMEs enfrentarem seus desafios de sobrevivência passaria pela formação de redes cooperativas sendo os vínculos estabelecidos entre as empresa tão importantes quanto à noção prementemente econômica de reduções de custos via usufruto de economias de escala e redução das porosidades do processo produtivo. Essas redes, segundo Santos, Crocco e Lemos (2001) poderiam ser estabelecidas de duas formas:

- redes horizontais: as PMEs podem, coletivamente atingir economias de escala acima da capacidade individual de cada empresa; realizar compras conjuntas de insumos; atingir uma escala ótima no uso da maquinaria; realizar marketing conjunto; e combinar suas capacidades de produção para atender pedidos de grande escala.

- redes verticais: as PMEs podem se especializar no seu core business e dar lugar a uma divisão externa do trabalho, mas interna ao local, através da interação entre usuários e produtores; podem reduzir os riscos associados à introdução de novos produtos e o tempo de transição da inovação entre o projeto e o mercado.

Para Porter (1998), a rede de empresas consiste em um tipo de agrupamento empresarial, que tem como objetivo o fortalecimento das atividades de cada participante, sem que haja necessariamente, laços financeiros entre si. A participação em redes possibilita às empresas complementar-se umas às outras, nos aspectos técnicos e mercadológicos.

A constituição de redes é importante porque a firma tem incertezas quanto à escolha de tecnologias, as redes desenvolvem funções para lidar com essas incertezas, ou seja, a integração das firmas em redes permite a essas administrarem as incertezas de modo mais eficiente, tendo portanto, impactos positivos sobre a competitividade. Portanto, a participação em 
redes pode proporcionar um largo conjunto de experiências, estimulando o aprendizado e gerando conhecimento coletivo, e este aprendizado promovido entre os agentes é considerado como uma das suas maiores contribuições. As redes definem as firmas não como uma entidade isolada que toma decisões de acordo com seus custos e benefícios, mas sim como uma processadora de informações e um centro de competências.

A governança num cluster refere-se aos diferentes modos de coordenação, intervenção e participação dos diversos agentes (Estado, em seus vários níveis, empresas, cidadãos e trabalhadores, organizações não-governamentais) nos processos de decisão locais e nas diversas atividades que envolvem a organização dos fluxos de produção, assim como o processo de geração, disseminação e uso de conhecimentos. Estes modos e relações de governança podem existir ou não em uma estrutura produtiva particular. Existem 4 tipologias de governança, segundo Campos e Vargas (2003):

O tipo 1 mostra uma situação em que a presença de poucos segmentos na cadeia produtiva e a ausência de grandes firmas sugere a existência de uma forma de administração em redes que pode ser combinada com a presença de instituições associativas que tem um papel significante na coordenação de ações cooperativas entre as firmas. Descreve uma aglomeração com uma infra-estrutura de conhecimento restrita e inestruturada. Também se assume uma limitação no alcance de gerenciar processos de aprendizado interativo e as principais fontes de informação e conhecimento são providos externamente. Neste aspecto, os empresários locais têm um papel passivo em adquirir novos conhecimento através de rotinas de aprenderfazendo ou aprender-usando.

No tipo 2, a configuração da estrutura produtiva difere da anterior em relação à distribuição do tamanho das firmas. A presença de grandes firmas sugere governança hierárquica para o sistema como um todo. Pode também estar combinado, como no tipo 1. A diferença é dada pelas formas de relações entre as firmas, uma vez que o alto grau de relações verticais com reduzida divisão de trabalho tende a reduzir a intensidade das relações entre as firmas. Descreve aquele aglomerado que apesar da falta de infra-estrutura de conhecimento se lança a administrar fluxos de conhecimentos, tem um número de firmas engajadas em adquirir e/ou gerar novos conhecimentos. Entretanto, essa capacidade inovativa tende a permanecer "enclausurada" em um pequeno grupo de firmas desde que exista um canal de distribuição no cluster. Como as estruturas institucionais e organizacionais associadas com o sistema de conhecimento têm um alcance muito limitado em promover processos de aprendizagem interativos, as dinâmicas inovativas da aglomeração permanecem pobres como um todo.

No Tipo 3, a grande divisão do trabalho incrementa a densidade da configuração da estrutura, na ausência de grandes firmas; a governança por redes predomina no sistema. Entretanto é possível uma relação mais intensa entre grupos de médias e pequenas firmas durante a formação de redes de subcontratação. A estrutura institucional e organizacional relacionadas à geração e difusão de informação e conhecimento estão muito bem estruturadas e sistematizadas, a capacidade das firmas em desenvolver mecanismos de aprendizagem é muito baixo e baseada externamente. Então, mesmo considerando que a existência à ação de fornecedores de conhecimento a base para a difusão de inovações por mecanismos de aprendizagem interativa as dinâmicas de competitividade e inovação de um cluster está barrada pela natureza passiva dos mecanismos de aprendizagem da firma.

Finalmente, no tipo 4, a configuração do sistema produtivo é o mais complexo de todos os tipos apresentados e sugere uma governança hierárquica para o sistema como um todo combinado com uma grande variedade de outros tipos de administrações particulares entre grupos de firmas. Descreve um caso que pode ser visto como um exemplo perfeito do e auto-sustentado do sistema local de inovação. Primeiramente, a infra-estrutura de conhecimento 
que da base aos processos de difusão em nível local são estruturados e sistêmicos. Em segundo lugar, as firmas têm uma alta capacidade de gerenciar processos de aprendizagem interativa. Finalmente, as principais fontes de informação e conhecimento usadas para alimentar os processos de inovação estão localizadas nos arranjos. Os empresários têm parte ativa no gerenciamento dos fluxos de conhecimento de fora do cluster.

Com o passar dos tempos pode-se notar uma transição da era industrial para uma baseada no conhecimento, um novo padrão de acumulação baseado em novas práticas de produção, comercialização e consumo de bens e serviços, novos aparatos e instrumentais científicos e produtivos. Tudo isso acompanhado de mudanças significativas nas formas de organização, gestão e de atuação de empresas e demais instituições de ensino, pesquisa e desenvolvimento, promoção e financiamento. Isto implica que o tempo necessário para lançar e comercializar novos produtos tem-se reduzido e que os ciclos de vida dos produtos e processos estão também menores. Tal percepção tem levado alguns autores a qualificar a nova economia como "economia da inovação perpétua" elemento chave da competitividade dinâmica e sustentável (CASSIOLATO; LASTRES, 2003).

O processo de inovação tecnológica geralmente resulta da interação que ocorre no processo de aprendizado, interação que acontece não somente em ambientes conectados com P\&D, mas também no cotidiano da atividade econômica, investigando, produzindo e fazendo. Essas interações podem ocorrer dentro da firma, entre firmas e clientes, entre diferentes firmas, como também entre firmas e outras organizações públicas ou privadas (EDQUIST; JOHNSON apud BUSTAMANTE, 1997).

A inovação e o conhecimento são os principais fatores que definem a competitividade e o desenvolvimento de nações, regiões, setores, empresas e até de indivíduos. A concorrência está cada vez mais baseada em conhecimento e na organização dos processos de aprendizado. A inovação constitui-se em um processo de busca e aprendizado, o qual, enquanto dependente de interações, é determinado e influenciado por formatos institucionais e organizacionais específicos. Pode-se concluir portanto, que a chave para o sucesso em inovações está na interação.

O processo de inovação é interativo e conta com a contribuição de vários agentes econômicos e sociais que possuem diferentes tipos de informações e conhecimentos. A competitividade dos agentes econômicos depende cada vez mais da capacidade de lidar com a informação para transformá-la em conhecimento. No momento atual, a competição não se dá somente via preços, o importante não é apenas ter acesso à informação ou possuir um conjunto de habilidades, mas sim ter capacidade para adquirir novas habilidades e conhecimento.

O processo inovativo é necessário para se garantir maior confiabilidade, durabilidade e design de um produto, entretanto, se a empresa não tiver uma boa capacidade de marketing, de modo a potencializar as qualidades de seu produto, os avanços inovativos não se expressarão como deveriam. Conclui-se que é importante para a empresa ter um planejamento estratégico (POSSAS, 1993).

A inovação tem sido a fonte de destruição de velhas formas de trabalho e a origem de novos tipos de emprego (processo destruição criadora). As firmas podem concorrer através de sua capacidade de inovar e não só através do preço (SCHUMPETER, 1982).

O conceito de novas combinações de Schumpeter (1982) engloba cinco possibilidades: (1) Introdução de um novo bem, um produto/serviço que seja desconhecido do consumidor, ou pode ser até mesmo uma nova qualidade acrescida ao bem. (2) Introdução de um novo método de produção, que pode ser um novo processo, uma nova tecnologia em produção e pode ser também uma nova forma de comercializar um produto. (3) Abertura de um novo mercado, ou seja, introduzir o produto ou a marca em um mercado 
ainda não explorado pelo produtor, pode ser um mercado recém-criado, ou mesmo um mercado que já exista há algum tempo. (4) Conquista de uma nova fonte de oferta de matérias-primas ou de bens semimanufaturados, nesse caso a fonte pode já existir, mas ainda não ter sido utilizada para esse fim. (5) Estabelecimento de uma nova organização de qualquer indústria, como o estabelecimento de uma posição de monopólio, por exemplo.

Para que isso seja possível tem que haver uma cooperação, "cooperação competitiva" que é uma condição que potencializa o desempenho industrial, pois maximiza a eficiência e a competitividade.

Pode-se distinguir duas formas de cooperação entre firmas : a vertical e a horizontal. A cooperação vertical estabelece relações entre firmas que desenvolvem atividades complementares em diferentes estágios da cadeia produtiva e a cooperação horizontal ocorre entre empresas do mesmo porte, que atuam num mesmo segmento e pode envolver instituições de apoio (MYTELKA; FARINELLI apud GEREMIA, 2003).

O processo de geração de inovação pode trazer mais vantagens competitivas para um aglomerado de PMEs, como a da região Londrina. As políticas de inovação voltadas para as PMEs tentam dar a essas empresas condições para superar suas limitações de crédito, falta de recursos destinados a P\&D e maior poder político. As pequenas e médias empresas não têm consciência dos ganhos de competitividade trazidos pelas oportunidades de negócio associadas às inovações. As PMEs somente introduzem inovações quando percebem as oportunidades de negócio ou quando fornecedores e clientes exigem algo diferente.

Uma política de difusão da inovação para PMEs tem mais chances de sucesso quando são implementadas em nível regional. As instituições regionais tais como centro de pesquisa e ensino, universidades e centros de treinamento possuem um papel importante na identificação das fraquezas das PMEs na adoção de tecnologias de informação e de comunicação. Essa política deve privilegiar um conjunto de indústrias em articulação com outros setores da economia para aumentar a capacitação tecnológica e com isso melhorar a competitividade.

Rovere (1999) inclui como políticas de inovação para as PMEs os seguintes programas:

- programas de capacitação tecnológica que apóiam $\mathrm{P} \& \mathrm{D}$, fornecem informações, monitoram desenvolvimento tecnológico e estimulam estratégias e transferência de tecnologia.

- programas que coloquem especialistas técnicos nas firmas para promover educação tecnológica e identificar possibilidades de melhoria, estimulam o uso de consultores privados, fornecem informações tecnológicas através de centros de tecnologia e de produtividade estatais e estimulam a conscientização.

- programas-ponte, onde o governo fornece educação técnica e vocacional, prescreve praticas baseadas em experiências de sucesso no uso de Tecnologias da Informação e Comunicação, desenvolve pólos de ciência e tecnologia, define normas e coordena esforços entre as agências.

A consolidação de um cluster ou arranjo produtivo depende da ação conjunta do setor público e privado para incrementar quantitativa e qualitativamente: os serviços nas áreas de ciência e tecnologia, os serviços técnicos especializados, o ensino e a formação de mão-de-obra tecnicamente preparada para atender aos requisitos da nova indústria, prestar os serviços financeiros e garantir a existência de infra-estrutura física e o apoio à produção e à comercialização.

\section{A Indústria Moveleira no Brasil e no Mundo}

A indústria mundial de móveis é uma indústria tradicional constituída predominantemente por pequenas empresas; até os anos 50 elas visavam atender quase exclusivamente o mercado interno dos seus respectivos países. O comércio internacional de móveis ampliou de forma significativa a partir dos anos 70 , sob a liderança da Itália. O principal 
importador de móveis é os EUA, respondendo por 1/ 5 das importações mundiais.

As exportações também estão concentradas nos países desenvolvidos. A Europa participa com mais de $60 \%$ das exportações mundiais (em primeiro lugar Itália e em segundo a Alemanha). Os principais segmentos do comércio internacional de móveis são: móveis de madeira, com $40 \%$ do total exportado, cadeiras e assentos, com 30\%, móveis de metal, $8 \%$ e móveis plásticos, $1 \%$. Os principais mercados produtos e consumidores são apresentados na Tabela 1.

Tabela 1.Principais países produtores e consumidores de móveis (1996).

\begin{tabular}{lcccc}
\hline País & Consumo Aparente & \multicolumn{2}{c}{ Produção } \\
\hline & US\$ Milhões & $\%$ & US\$ Milhões & $\%$ \\
Estados Unidos & 58.739 & 37,7 & 48.660 & 31,2 \\
Alemanha & 19.177 & 12,3 & 18.414 & 11,8 \\
França & 12.112 & 7,8 & 7.502 & 4,8 \\
Itália & 11.921 & 7,7 & 16.368 & 10,5 \\
Reino Unido & 10.052 & 6,5 & 7.502 & 4,8 \\
Japão & 6.927 & 4,4 & & \\
Espanha & 6.559 & 4,2 & 4.092 & 2,6 \\
Subtotal & 125.487 & 80,6 & 102.538 & 65,8 \\
Outros & 30.242 & 19,4 & 53.191 & 34,2 \\
Total & 155.729 & 100 & 155.729 & 100 \\
\hline
\end{tabular}

Fonte: Gorini (1998).

Durante a década de 90, a cadeia produtiva de madeira e móveis em termos mundiais sofreu grandes transformações com conseqüentes ganhos de produtividade, não somente no que referiu à introdução de equipamentos automatizados na área produtiva e a utilização de novas técnicas de gestão, como também ao uso de outras fontes de matérias-prima.. O setor continuou fragmentado, mesmo em face das atualizações tecnológicas e administrativas; verificouse a baixa incidência de fusões, parcerias e outros mecanismos associativos e o setor tem apresentado marcantes características regionais (SANTOS; PAMPLONA; FERREIRA, 1998).

Uma tendência verificada internacionalmente é o crescimento do uso de médium-desinty fiberboard (MDF), sendo para reduzir custos, mas mantendo o padrão de qualidade, verifica-se a mistura de diversos materiais no mesmo móvel (MDF nas partes frontais, fundos de chapa dura e as laterais feitas de aglomerado). Outra tendência verificada nos países desenvolvidos é o conforto e a funcionalidade do móvel. As tendências para o futuro são de um móvel prático, padronizado, de baixo custo, e confeccionado a partir de madeira de reflorestamento (FERREIRA, 2002).

A indústria de móveis reúne diversos processos de produção, envolve diferentes matérias- primas e uma grande diversidade de produtos finais. A indústria é segmentada em função dos materiais que os móveis são confeccionados (madeira, metal e outros) e o uso a que são destinados (em especial, móveis para residência e escritório). Os fatores que determinam a competitividade da indústria de móveis se relacionam a novas matérias-primas, design, especialização da produção, estratégias comerciais e de distribuição, entre outros. Outra característica é a especialização das empresas na fabricação de um ou dois tipos de móveis em função de aspectos técnicos e mercadológicos. Há predominância de pequenas e médias empresas que utilizam intensamente a mão-de-obra em seu processo produtivo e atuam em um mercado bastante segmentado (GORINI, 1998).

As médias e pequenas empresas não investem em design próprio devido ao custo desse investimento e o retorno ser baixo ou negativo. O único fator de inovação próprio da indústria de móveis é dado pelo design, ao proporcionar a diferenciação do produto frente aos demais, se constituindo em dos elementos chaves para as condições de concorrência. As empresas procuram observar as principais tendências de mercado e elaborar um novo modelo que, na verdade, é a cópia de diversos modelos em um único produto. As grandes empresas procuram desenvolver seus próprios projetos de design ou compram e adaptam projetos estrangeiros (SANTOS, PAMPLONA; FERREIRA,1998).

A indústria brasileira de móveis apresenta produção geograficamente dispersa por todo território nacional, localizando-se principalmente na região centro-sul do país, que responde por $90 \%$ da produção nacional e $70 \%$ da mão-de-obra do setor. No Brasil, 
assim como em outros países, a indústria moveleira caracteriza-se pela organização em pólos regionais, sendo os principais: Bento Gonçalves, no Rio Grande do Sul; São Bento do Sul, em Santa Catarina; Arapongas no Paraná; Mirassol, Votuporanga e São Paulo, em São Paulo; Ubá em Minas Gerais; e Linhares no Espírito Santo.

Essas empresas são formadas por mais de 15.000 micro, pequenas e médias empresas que geram mais de 177.000 empregos. São empresas familiares, tradicionais e na grande maioria de capital inteiramente nacional. No segmento de móveis para escritório pode se notar um certo interesse de empresas estrangeiras em adentrar no mercado nacional.

A indústria de móveis caracteriza-se, principalmente, por dois aspectos: elevado número de micro e pequenas empresas (capital inteiramente nacional) e grande absorção de mão-de-obra. $\mathrm{O}$ faturamento da indústria moveleira no ano de 2003 foi da ordem de 8,8 bilhões de reais, no qual, $60 \%$ referem-se a móveis residenciais, $25 \%$ a móveis de escritório e $15 \%$ a móveis institucionais, escolares, médico-hospitalares, móveis para restaurante, hotéis e similares. O Brasil ocupa a décima colocação mundial na produção de móveis, $10^{\circ}$ lugar em consumo, $24^{\circ}$ colocação em exportação e $35^{\circ}$ lugar na importação de móveis (ABIMÓVEL, 2003).

O Gráfico 1 apresenta a evolução das exportações brasileiras de móveis entre 1998 e 2002 . Os móveis mais exportados nos últimos anos foram, sala de jantar, sala de estar e cozinhas (33\%), dormitórios (32\%) e outros.

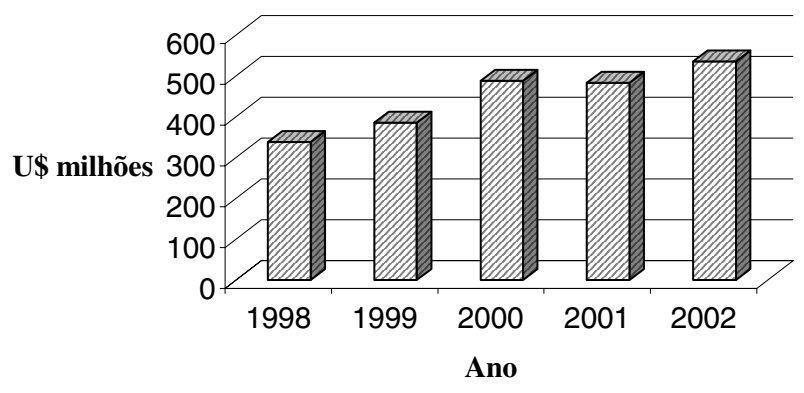

Gráfico 1 - Exportações de Móveis - Brasil 1998/2002. Fonte: Abimóvel (2003).

Os estados de São Paulo, Rio Grande do Sul, Santa Catarina e Paraná, respondem por cerca de $82 \%$ da produção nacional. O consumo nacional é suprido basicamente pela produção interna, com baixo volume de importação de móveis. Os principais pólos moveleiros do Brasil são apresentados no Quadro 1.

Os pólos se caracterizam por um alto grau de verticalização, além de elevada fragmentação. Mirassol e Ubá são os mais verticalizados, por outro lado São Paulo, Bento Gonçalves e São Bento do Sul transferem em torno de $50 \%$ de suas etapas produtivas para terceiros. A indústria de móveis precisa avançar bastante em direção ao paradigma competitivo dominante nos países desenvolvidos, o que significa: a) especialização e desverticalização das empresas que trabalham com produtos mais complexos, apoiados em redes organizadas e eficientes; b) "upgrade" das linhas produtivas automatizadas dos produtos padronizados mais simples em direção à automação mais flexível, capaz de permitir maior diferenciação de produtos (SANTOS, PAMPLONA; FERREIRA, 1998). 
Quadro 1- Principais Pólos Moveleiros -Brasil

\begin{tabular}{|c|c|c|c|c|c|}
\hline Pólo Moveleiro & UF & Número de & Empregados & Principais & Principais Produtos \\
\hline Ubá & Minas Gerais & $\begin{array}{l}\text { Empresas } \\
153\end{array}$ & 3.150 & $\begin{array}{l}\text { Mercados } \\
\text { Minas Gerais, São } \\
\text { Paulo, Rio de } \\
\text { Janeiro e Bahia }\end{array}$ & $\begin{array}{l}\text { Cadeiras, dormitórios, salas, } \\
\text { estantes e móveis sob } \\
\text { encomenda }\end{array}$ \\
\hline $\begin{array}{l}\text { Bom Despacho e Martinho } \\
\text { Campos }\end{array}$ & Minas Gerais & 117 & 2.000 & Minas Gerais & $\begin{array}{l}\text { Cadeiras, dormitórios, salas, } \\
\text { estantes e móveis sob } \\
\text { encomenda }\end{array}$ \\
\hline Arapongas & Paraná & 145 & 5.500 & Todos os Estados & $\begin{array}{l}\text { Móveis retilíneos, estofados, } \\
\text { de escritório e tubulares }\end{array}$ \\
\hline Votuporanga & São Paulo & 350 & 7.000 & Todos os Estados & $\begin{array}{l}\text { Cadeiras, armários, estantes, } \\
\text { mesas, dormitórios, estofados } \\
\text { e móveis sob encomenda em } \\
\text { madeira maciça. }\end{array}$ \\
\hline $\begin{array}{l}\text { Mirassol, Jaci, Bálsamo e } \\
\text { Neves Paulista }\end{array}$ & São Paulo & 80 & 3.000 & $\begin{array}{l}\text { São Paulo, Minas } \\
\text { Gerais, Rio de } \\
\text { Janeiro, Paraná e } \\
\text { Nordeste }\end{array}$ & $\begin{array}{l}\text { Cadeiras, salas, dormitórios, } \\
\text { estantes, mesas, dormitórios, } \\
\text { estofados e móveis sob } \\
\text { encomenda em madeira } \\
\text { maciça }\end{array}$ \\
\hline Tupã & São Paulo & 54 & 700 & São Paulo & $\begin{array}{l}\text { Mesas, racks, estantes, } \\
\text { cômodas e móveis sob } \\
\text { encomenda }\end{array}$ \\
\hline $\begin{array}{l}\text { São Bento do Sul e Rio } \\
\text { Negrinho }\end{array}$ & $\begin{array}{c}\text { Santa } \\
\text { Catarina }\end{array}$ & 210 & 8.500 & $\begin{array}{l}\text { Exportação, } \\
\text { Paraná, } \\
\text { Negrinho e } \\
\text { Paulo }\end{array}$ & $\begin{array}{l}\text { Móveis de Pínus, sofás, } \\
\text { cozinhas e dormitórios }\end{array}$ \\
\hline Bento Gonçalves & Rio Grande do Sul & 130 & 7.500 & $\begin{array}{l}\text { Todos os estados e } \\
\text { exportação }\end{array}$ & $\begin{array}{l}\text { Móveis retilíneos, móveis de } \\
\text { pínus e metálicos (tubulares) }\end{array}$ \\
\hline Lagoa Vermelha & Rio Grande do Sul & 60 & 1.800 & $\begin{array}{l}\text { Rio Grande do Sul, } \\
\text { São Paulo, Paraná, } \\
\text { Rio Negrinho e } \\
\text { Exportação }\end{array}$ & $\begin{array}{l}\text { Móveis retilíneos e móveis de } \\
\text { pinus }\end{array}$ \\
\hline
\end{tabular}

Fonte: Gorini(1998)

Algumas deficiências ainda persistem no setor: a) a grande verticalização da produção industrial de móveis; b) a carência de fornecedores especializados em partes e componentes de móveis; c) a incipiente normatização técnica; d) a elevada informalidade; e) os baixos investimentos em design e pesquisa de mercado (SERCONI, 2003).

\section{Análise das Pesquisas Realizadas no Cluster de Londrina e Região}

O pólo moveleiro de Londrina está localizado na região norte do Estado do Paraná. É composto por 114 industrias, com destaque na fabricação de móveis residenciais e de escritório. Foram visitadas 40 empresas e 10 concordaram em responder ao questionário adaptado do Projeto Arranjos Produtivos Locais SEBRAE (SEBRAE, 2002). Das empresas moveleiras pesquisadas, $60 \%$ atuam no mercado há mais de 10 anos, em média as empresas têm 15 anos de atividade. A principal atividade exercida pelos donos antes de serem proprietários das empresas era a de marceneiro. 90\% das empresas tem seu capital de origem nos próprios sócios, sendo que em nenhuma empresa o capital de origem veio de fontes alternativas como por exemplo, instituições financeiras, através de adiantamento de matérias por fornecedores ou de recursos por clientes, entre outras fontes.

Os móveis produzidos pelas empresas da região de Londrina são em sua grande maioria móveis residenciais. $100 \%$ das empresas pesquisadas fabricam armários e estantes e móveis para dormitório, $90 \%$ fabricam móveis para cozinha e banheiro, também há outros tipos de móveis residenciais fabricados como mesas, móveis de assento, infantis e de jardins. Algumas empresas 
também fabricam móveis de escritório, mas nenhuma empresa da região fabrica móveis de uso público. O principal material utilizado na fabricação é a madeira, seguida de metal, vidro e tecidos.

As empresas situadas na região são PMEs, com predominância das pequenas empresas, as quais apresentam um quadro de funcionários inferior a 15 empregados. As principais dificuldades enfrentadas pelas empresas nos primeiros anos de fundação foram à contratação de empregados qualificados $70 \%$, custo ou falta de capital para aquisição de máquinas e equipamentos com $70 \%$ e custo ou falta de capital de giro com $60 \%$ das empresas pesquisadas.

O principal mercado onde as empresas vendem seus produtos é o local 83\%, e o nacional com $17 \%$. Em relação à compra de insumos, $67 \%$ é comprado no mercado local e $33 \%$ no mercado nacional. Esta realidade comprova a característica de um cluster, de que os fornecedores tendem a localizar-se próximos ao cluster, exercendo um importante papel no desenvolvimento do mesmo (CASSIOLATO; LASTRES, 2003).

Os principais canais de comercialização são: loja do próprio fabricante $(60 \%)$ e pequenos varejistas (40\%). Os fatores de sucesso destacados na comercialização dos produtos pelas as empresas foram:

Tabela 2. Fatores de sucesso na comercialização.

\begin{tabular}{l|c|c|c|c|c|c}
\hline \multirow{2}{*}{ Fatores } & \multicolumn{6}{|c}{ Grau de importância* } \\
\cline { 2 - 8 } & Um & Dois & Três & Quatro & Cinco & Total \\
\hline Preço do produto & 0 & 2 & 1 & 5 & 2 & 10 \\
\hline Marca do produto/tradição da empresa & 1 & 0 & 0 & 5 & 4 & 10 \\
\hline $\begin{array}{l}\text { Serviços pós-venda/assistência ao } \\
\text { consumidor }\end{array}$ & 0 & 0 & 0 & 7 & 3 & 10 \\
\hline Propaganda/Publicidade & 4 & 2 & 0 & 3 & 0 & 9 \\
\hline Prazo e confiabilidade nos prazos & 0 & 0 & 0 & 7 & 3 & 10 \\
\hline Estilo/Desenho & 1 & 0 & 0 & 7 & 2 & 10 \\
\hline
\end{tabular}

Fonte: elaboração dos autores.

Grau de importância*: Um (sem importância), Dois (pouco importante), Três (indiferente), Quatro (importante), Cinco (muito importante) e Total (número de empresas pesquisadas).
Como vantagem por estarem instaladas na região de Londrina, as empresas apontaram: a proximidade com os clientes e fornecedores e a infra-estrutura disponível de serviços. As desvantagens apontadas foram: a falta de mão-de-obra qualificada, a não proximidade com produtores de equipamentos, a inexistência de programas governamentais e a ausência de universidades e centros de pesquisa.

As principais transações que as empresas realizam localmente são: aquisição de insumos e matérias primas (7 empresas das 10 pesquisadas), aquisição de componentes de peças (8 empresas), aquisição de serviços (8 empresas) e vendas de produto (todas as empresas pesquisadas). Como ilustra a Tabela 3 abaixo:

Tabela 3. Transações locais.

\begin{tabular}{|l|l|l|l|l|l|l|}
\hline \multirow{2}{*}{\multicolumn{1}{|c|}{ Tipos de transações }} & \multicolumn{7}{c|}{ Grau de importância* } \\
\cline { 2 - 9 } & Um & Dois & Três & Quatro & Cinco & Total \\
\hline Aquisição de insumos e matéria prima & 3 & 0 & 0 & 4 & 3 & 10 \\
\hline Aquisição de equipamentos & 5 & 2 & 1 & 1 & 1 & 10 \\
\hline Aquisição de componentes e peças & 2 & 0 & 0 & 5 & 3 & 10 \\
\hline Aquisição de serviços (manutenção, marketing) & 2 & 0 & 0 & 5 & 3 & 10 \\
\hline Vendas de produtos & 0 & 0 & 0 & 5 & 5 & 10 \\
\hline
\end{tabular}

Fonte: elaboração dos autores.

Grau de importância*: Um (sem importância), Dois (pouco importante), Três (indiferente), Quatro (importante), Cinco (muito importante) e Total (número de empresas pesquisadas).

Quanto às fontes de informação tecnológica, as empresas pesquisadas utilizam principalmente clientes locais, revistas e publicações especializadas, fornecedores locais de insumos, congressos e feiras comerciais e industriais do setor. O desenvolvimento ou incorporação de novas tecnologias se dá através da cooperação de empresas-clientes e nas unidades de produção das empresas. Portanto, as empresas têm uma estratégia de investir no canal de comunicação com seus clientes, mantendo contato para identificar possibilidades de melhoria e inovação em seus produtos. McFarlan (1998), diz que a conquista de vantagens através de sistemas de informação, requer gerenciamento eficiente, muita imaginação e um estreitamento na comunicação com o usuário. 
Segundo Santos, Pamplona e Ferreira(1998), o único fator de inovação próprio da indústria de móveis é dado pelo design, ao proporcionar a diferenciação do produto frente aos demais, se constituindo em um dos elementos chaves para as condições de concorrência. As empresas procuram observar as principais tendências de mercado e elaborar um novo modelo que, na verdade, é a cópia de diversos modelos em um único produto. As grandes empresas procuram desenvolver seus próprios projetos de design ou compram e adaptam projetos estrangeiros. As principais fontes de design utilizadas pelas empresas da região estão ilustradas no Gráfico 2 abaixo:

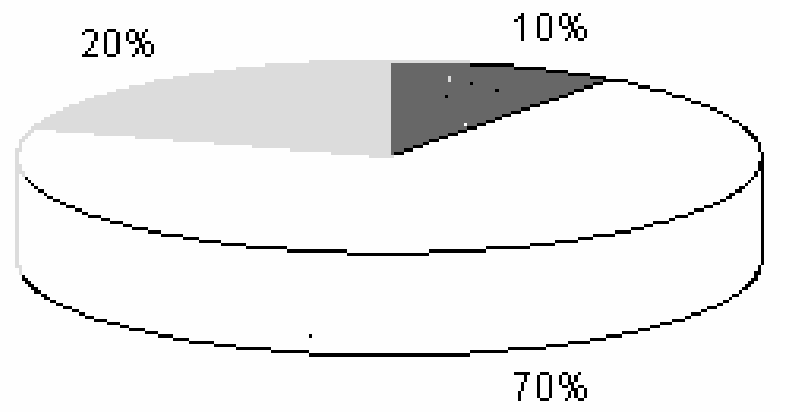

escritórios de design

parcerias com outras empresas

desenvolvimento interno

Gráfico 2. Fontes de design

Fonte: Pesquisa de campo

A cooperação entre empresas e agentes locais não foi verificada; não há cooperação entre empresas do mesmo porte (cooperação horizontal) e entre empresas que desenvolvam atividades complementares (cooperação vertical), como relata Geremia (2003). O grau de importância estabelecido pelas empresas foi o primeiro, ou seja, sem nenhuma importância, como se pode observar na Tabela 4 abaixo.
Tabela 4. Cooperação e Governança.

Fonte: Elaboração dos autores.

Grau de importância*: Um (sem importância), Dois (pouco importante), Três (indiferente), Quatro (importante), Cinco (muito importante) e Total (número de empresas pesquisadas).

Não foi verificada nenhuma instituição ou associação de apoio para as empresas. Poderia ser criada, segundo o Ministério da Ciência e Tecnologia, entidade tecnológica setoriais, as quais poderiam melhorar o desempenho das PMEs da região através de:

- projetos de P\&D e de inovação;

- estimulo e promoção de transferência de

\begin{tabular}{|l|c|c|c|c|c|c|}
\hline \multirow{2}{*}{ Ações conjuntas e de cooperação com agentes locais } & \multicolumn{7}{|c|}{ Grau de importância* } \\
\cline { 2 - 8 } & Um & Dois & Três & Quatro & Cinco & Total \\
\hline Para treinamento de empregados & 8 & 0 & 0 & 2 & 0 & 10 \\
\hline Para compra de insumos & 10 & 0 & 0 & 0 & 0 & 10 \\
\hline Para compra de equipamentos & 10 & 0 & 0 & 0 & 0 & 10 \\
\hline Para venda de produtos & 9 & 0 & 0 & 1 & 0 & 10 \\
\hline Para desenvolvimento e melhoria de produtos & 9 & 0 & 0 & 1 & 0 & 10 \\
\hline Para desenho e estilo de produtos & 10 & 0 & 0 & 0 & 0 & 10 \\
\hline Reivindicatórias junto ao poder público & 10 & 0 & 0 & 0 & 0 & 10 \\
\hline Obtenção de financiamento & 10 & 0 & 0 & 0 & 0 & 10 \\
\hline Viagens conjuntas - feiras & 9 & 0 & 0 & 1 & 0 & 10 \\
\hline
\end{tabular}

- organização de bancos de dados em inovações, tecnologia e informações empresariais;

- programas de gestão de qualidade e gestão do meio ambiente;

- organização de eventos, simpósios e exibições;

- e cooperação com associações de consumidores.

As empresas pesquisadas listaram algumas políticas que poderiam contribuir para o aumento da eficiência competitiva, $80 \%$ das empresas deu grau de importância significativa para as políticas, conforme a Tabela 5 abaixo. 
Tabela 5. Ações políticas.

\begin{tabular}{l|c|c|c|c|c|c}
\hline \multirow{2}{*}{ Ações de Políticas } & \multicolumn{7}{|c}{ Grau de importância* } \\
\cline { 2 - 8 } & Um & Dois & Três & Quatro & Cinco & Total \\
\hline Programas de capacitação profisssional e treinamento técnico & 0 & 0 & 0 & 7 & 3 & 10 \\
\hline Melhorias na educação básica & 1 & 0 & 0 & 6 & 3 & 10 \\
\hline Programas de apoio à consultoria técnica & 2 & 0 & 0 & 6 & 2 & 10 \\
\hline Estímulos à oferta de serviços tecnológicos & 2 & 0 & 0 & 6 & 2 & 10 \\
\hline Programas de acesso à informação (produção, tecnologia, etc.) & 2 & 0 & 0 & 6 & 2 & 10 \\
\hline Linhas de crédito e outras formas de financiamento & 2 & 0 & 0 & 6 & 2 & 10 \\
\hline Incentivos fiscais & 2 & 0 & 0 & 6 & 2 & 10 \\
\hline Políticas de funda de aval & 2 & 1 & 0 & 5 & 2 & 10 \\
\hline Programas de estímulo ao investimento (venture capital) & 2 & 0 & 0 & 6 & 2 & 10 \\
\hline
\end{tabular}

Fonte: elaboração dos autores.

Grau de importância*: Um (sem importância), Dois (pouco importante), Três (indiferente), Quatro (importante), Cinco (muito importante) e Total (número de empresas pesquisadas).

Para ampliar a infra-estrutura tecnológica, as empresas sugerem a criação de escolas técnicas e laboratórios de $\mathrm{P} \& \mathrm{D}$ que atendam às empresas da região, e disponibilidade e acesso a financiamentos com juros mais acessíveis.

Diante do exposto, a região de Londrina apresenta condições favoráveis para o desenvolvimento do cluster moveleiro. No entanto, faltam determinadas atitudes dos empresários e do governo, visando à implementação de políticas que estimulem o desenvolvimento de redes de cooperação locais para potencializar a formação do cluster. Pode-se verificar segundo a tipologia de Campos e Vargas (2003), uma aglomeração com uma infra-estrutura de conhecimento restrita e inestruturada, na qual os empresários locais possuem um papel passivo, isso vem a caracterizar o Tipo 1. Portanto, pode-se verificar que há formação de um cluster insipiente

\section{Notas Conclusivas}

O objetivo deste trabalho foi o estudo do cluster moveleiro da região de Londrina. A literatura utilizada foi referente à formação de clusters ou arranjos produtivos, formas de inovação e design. Procurouse identificar o estágio de desenvolvimento desse cluster e seu potencial de crescimento. A partir dos resultados da pesquisa de campo, verificou-se que o potencial de crescimento do cluster é grande. Porém, a ausência de relações de cooperação entre os empresários da região, para compra de insumos, para a comercialização da produção, para o desenvolvimento e melhorias de produto, entre outros, resultam em um cluster insipiente que vai pouco além de um aglomerado geográfico de empresas de um mesmo segmento industrial, dados os baixos elos verticais (fornecedores -empresas) e a inexistência de elos verticais (cooperação entre empresas) e de elos multilaterais( Sindicato de produtores, instituições de pesquisa e ensino, firmas.)

A participação do setor público no apoio e estimulo ao desenvolvimento das empresas é precário. Portanto, é necessária a presença de governos e instituições ou associações de apoio para a construção de redes de cooperação na região, que visem o aumento da competitividade e sustentabilidade do setor produtivo. A formação de um cluster se faz necessário para o desenvolvimento das empresas e da comunidade, pois traz inúmeros benefícios econômicos, culturais e sociais. Por todos esses fatores, percebe-se que há um longo caminho a ser percorrido para a consolidação do cluster regional pesquisado.

\section{Referência}

ABIMÓVEL. Brasil mobiliando o mundo. Disponível em: $<$ http://www.abimovel.com.br>. Acesso em: 30 mar. 2003.

BUSTAMANTE, P.M.A. Arranjos produtivos e inovativos locais: o caso do pólo moveleiro de Ubá- MG. 2003. $128 f$. Dissertação (Mestrado em Economia) - Universidade Federal de Minas Gerais, Belo Horizonte, 2003.

CAMPOS, R.; VARGAS, M. Forms of governance, learning mechanisms and localized innovation: a comparative, analysis in local productive systems in Brazil. In: CONFERENCIA INTERNACIONAL SOBRE SISTEMAS DE INOVAÇÃO E ESTRATÉGIAS DE DESENVOLVIMENTO PARA O TERCEIRO MILÊNIO, 2003, Rio de Janeiro. Anais... Rio de Janeiro: GLOBELICS, 2003.

CASSIOLATO, J. E.; LASTRES, H. M. M. Arranjos e Sistemas Produtivos Locais na Indústria Brasileira. In: CASSIOLATO, J. E.; LASTRES, H. M. M(Org.) Parcerias Estratégicas. Rio de Janeiro:UFRJ, 2003. 
CUNHA, S. K.; OLIVEIRA, M. A.; CUNHA, J. C. Clusters: novo padrão de especialização da indústria paranaense na década de 90. In: SEMEAD. Política e Gestão Tecnológica, 6., 2003. Disponível em: <http:// www.ead.fea.usp.br/Semead/6semead/PGT.htm>. Acesso em: 8 set. 2003 .

CUNHA, S. K.; TODERO, P. Clusters: novas trajetórias para o desenvolvimento do Sudoeste do Paraná. IV SEMEAD. Política e Gestão Tecnológica, 4., 2001. Disponível em: <http://www.ead.fea.usp.br/Semead/ 4semead/PGT.htm>. Acesso em: 8 set. 2003.

DIAS, A. R.; PEDROZO, E. A. Configuração da estrutura de cluster na pecuária de corte do município de Gurupi, Tocantins, Amazônia Legal. In: COLOQUIO SOBRE TRANSFORMACIONES TERRITORIALES "SOCIEDAD, TERRITORIO Y SUSTENTABILIDAD: PERSPECTIVAS DESDEELDESARROLLOREGIONAL Y LOCAL”,6., 2002, Montevideo. Mesa Temática: Innovacion, Tecnologia y Desarrollo local/regional, 2002.

FERREIRA, O. P. Prospectiva Tecnológica da cadeia produtiva madeira e móveis. São Paulo: Instituto de Pesquisas Tecnológicas, 2002.

GEREMIA,F. Dinâmica competitiva e processos de aprendizagem do arranjo produtivo moveleiro da região oeste de Santa Catarina. 2003. 134 f. Dissertação (Mestrado em Economia) - Universidade Federal de Santa Catarina, Florianópolis, 2003.

GORINI, A. P. Panorama do setor moveleiro no Brasil, com ênfase na competitividade externa a partir do desenvolvimento da cadeia industrial de produtos sólidos de madeira. Rio de Janeiro: BNDES, 1998. (Panorama Setorial, 8).
SANTOS, R. M. S.; PAMPLONA, T.; FERREIRA, M. J. B. Design como Fator de Competitividade na Indústria Moveleira. São Paulo: Sebrae/Finep/Abimóvel/Fecamp/ Unicamp-IE-Neit, 1998.

McFARLAN, F.W. A tecnologia da informação muda a sua maneira de competir. In: MONTGOMERY, C. A; PORTER, M. E. Estratégia: a busca da vantagem competitiva. Rio de Janeiro: Campus, 1998.

PORTER, M. E. Estratégia competitiva: técnicas para análise de indústrias e da concorrência. Rio de Janeiro: Campus, 1998.

POSSAS, M. S. Concorrência e Competitividade. 1993. 221 f. Dissertação (Doutorado em Economia) - Instituto de Economia da Unicamp, Campinas, 1993.

ROVERE, L. L. As pequenas e médias empresas na economia do conhecimento: implicações para políticas de inovação. In: LASTRES, H; ALBBAGLI, S. de (Org.). Informação e Globalização na era do Conhecimento. Rio de Janeiro: Campus, 1999. p.73-96.

SANTOS, F.; CROCCO, M.; LEMOS, M. B. Arranjos e sistemas produtivos locais em espaços industriais periféricos: estudo comparativo de dois casos brasileiros. Belo Horizonte, 2001. (Texto para Discussão 182).

SCHUMPETER, J. A. Teoria do desenvolvimento econômico. São Paulo: Nova Cultural, 1982. 239 p.

SEBRAE. Subsídios para a identificação de clusters no Brasil: atividades da indústria. São Paulo, 2002.

SERCONI, L. Os pólos moveleiros do Sul do Brasil: estratégias de crescimento, inovação e gestão empresarial. 2003. 128 f. Dissertação (Mestrado em Administração) Universidade Estadual de Londrina, Londrina, 2003. 